\title{
It's Called Fruit Juice So It's Good For Me........ Right?: An Exploratory Study Of Children's Fruit Content Inferences Made From Food Brand Names And Packaging
}

Jill K. Maher, Ph.D., Robert Morris University, USA

\begin{abstract}
Food and beverage marketing to children has come under extreme scrutiny in the past several years as it has been recognized as a potential contributor to the childhood obesity epidemic. It is not the purpose of this research to make the connection between food marketing and childhood obesity. However, an important aspect in fighting this epidemic is corporate responsibility in conveying clear brand information. From an information processing framework, this research examines the inferences made by children about fruit content in children's food and beverage products. It focuses on food products that are linked to fruit through signals of fruit in the brand name or packaging. Broadly speaking, this research examines the question, "when exposed to food product brand names and packaging with fruit-like cues, what do children infer about the amount of fruit found in these products?" Findings illustrate extreme confusion in the marketplace. Research addressing how children perceive brand names and other elements of food packaging is important for brand strategy and public policy.
\end{abstract}

Keywords: Food Marketing; Children; Obesity; Packaging; Branding; Ethics

\section{INTRODUCTION}

\begin{abstract}
Tile some reports have stated that marketers spend approximately 10 billion dollars per year (IOM 2006) on marketing children's food products, the most recent FTC report on marketing food to children and adolescents states that this number is approximately \$1.6 billion (FTC 2008). Specifically, the report states that expenditures directed to youth ages 2 to 17 represent 17 percent of the total 2006 marketing budget for food marketers. Further, statistics suggest that children influence another 500 billion dollars of annual household spending (IOM 2006). These figures suggest that children and youth are an important target segment for food and beverage marketers.
\end{abstract}

Food and beverage marketing to children has come under extreme scrutiny in the past several years, as it has been recognized as a potential contributor to the childhood obesity epidemic (IOM 2006). It is not the purpose of this research to make the connection between food marketing and childhood obesity. However, an important aspect in fighting this epidemic is corporate responsibility in conveying brand information in such a way that consumers can make their own informed evaluations and choice.

It has been reported that companies spend $\$ 195$ million on packaging and in-store display materials to reach children and adolescents (FTC 2008). Marketers of children's food products attract children at the point of purchase with brightly colored packages often including pictures of spokescharacters and vibrant images. These types of visual cues are intended to appeal to children and provide product signals that are understandable to them. 
However, if these cues are misleading to children and even parents, it may be difficult for them to appropriately evaluate these products and make good nutritional choices.

Members of the food and beverage industry, as well as entertainment and media companies, have been urged to be more proactive in encouraging better nutrition and fitness among the nation's youth by the 2005 joint FTC/HHS Workshop on Marketing, Self Regulation \& Childhood Obesity, and the subsequent Report issued in April 2006. Thus, addressing how children use marketing signals such as brand names and other elements of food packaging is important for brand strategy and public policy. The research presented here examines the inferences made by children about fruit content in some popular children's food and beverage products. It focuses on food products that are linked to fruit through pictures or signals of fruit in the brand name or product packaging (e.g., Berry Berry Kix Cereal). Specifically, this research examines the question, "when exposed to product brand names and packaging with fruit or fruit-like cues, what do children of different ages infer about the amount of fruit found in these products?" A review of relevant literature is provided followed by the methodology employed in the study. The results will be presented and finally the implications of this research will conclude the paper.

\section{THEORETICAL FRAMEWORK}

\section{Information Processing and Consumer Knowledge}

Consumers process marketer-dominated information leading to consumer knowledge every day. What consumers process and what they know strongly influences their product requests and consumer buying. Moving through a process starting with exposure to information, and moving through attention to information, perception or understanding of information, and ultimately the storage of information in consumer memory is referred to as consumer information processing (Hoyer and MacInnis 2010). Once information is stored, it becomes knowledge. The signals provided by marketers help consumers make inferences, or quick conclusions about different aspects of the product during information processing, specifically in the perception stage. These inferences are made by using existing knowledge. In other words, the knowledge one has will shape the inferences made (Blackwell, Miniard, and Engel 2006). An inference is "a conclusion that is derived from a given set of information on the basis of a rule that associates the information to the conclusion in some subjectively logical fashion" (Kardes 1993, pg. 163). For instance, the use of the color green in a product's packaging may encourage consumers to infer (or perceive) that the product is healthy or environmentally friendly. A picture of a town in Italy on the front of a box of pasta may make the consumer infer that the product was made in Italy or used by consumers in Italy. Kardes (1993) suggests that when lack of time and energy do not permit extensive external search (similar to a retail grocery environment), consumers may potentially rely on drawing inferences from marketing elements for product information. In fact, in an information acquisition study, the brand name was the most important characteristic of a product sought out by research participants (Jacoby, Szybillo and Busato-Schach 1977) as it is the element of marketing communications that provides the most information for consumers during information processing in the absence of additional product information. It makes intuitive sense then that consumers rely on this type of information in the supermarket environment. In food and beverage marketing, brand name and packaging signals are helpful to consumers (i.e., both adults and children) in making quick inferences, leading to an evaluation and choice.

Previous research has examined the relationship between the inferences made from food marketing practices and food evaluations and consumption. Recent research has demonstrated that consumers infer that a food will taste better if it is known to be unhealthy (Raghunathan, Naylor, and Hoyer 2006) and will also infer that foods that are low in cholesterol are also low in fat (Andrews, Netemeyer and Burton 1998). Further, with the recent focus on healthy food marketing, research has addressed the impact of product health claims on consumer inferences. Chandon and Wansink (2007) found that consumers infer that foods from restaurants claiming to be healthy (e.g., Subway), contain fewer calories than foods from restaurants not overtly making this claim. This finding supports the notion that consumers infer knowledge (e.g., amount of calories) from marketing communications. In another study by the same researchers, consumers upon seeing "low-fat" on a package, quickly inferred that the product was good for them, and consumed more. This research suggests that claims such as "low-fat" on a product's packaging give a biasing health halo to the food product potentially leading to poor nutritional choices/behaviors (Wansink and Chandon 2006). 
Previous research has examined the inferences children make within a food context. Specifically, Nguyen (2008) studied the inductive inferences made by children with regard to healthy and junky foods. The results suggested that children by age 4 can appropriately use evaluative criteria to categorize healthy and junky foods and they can further infer what these foods will do to their bodies. Children possess an evaluative category for healthy foods like skim milk, carrots, fish and fruit and a junky food evaluative category for foods like chips, cookies, and candy. Their ability to appropriately evaluate and classify these foods improves with age. Further, this research illustrated that children, by age 4, made distinct inferences from these foods to what the foods' effects would be on the body. This research suggests that children can make inferences similar to adults in the context of food.

\section{Research Objective and Contribution}

Using a consumer information processing framework, the current research examines the inferences made by children about the amount of fruit in fruit and fruit-like packaged products (e.g., Berry Berry Kix, Fruit Gushers, Capri Sun Juice Drink). This assessment is important as it is quite possible that fruit and fruit-like packaged products share a similar health halo as foods with positive health claims. Nguyen's (2008) research would suggest this as children possess a healthy food evaluative category which includes fruit and can make health inferences from this evaluative category. If children infer that fruit-like packaged products contain a lot of real fruit, placing them in the healthy food category, inaccurate evaluations will occur and potentially lead to the overconsumption of these products. Thus, this research has important implications for food marketing and public policy, as was as business ethics.

\section{LITERATURE REVIEW}

Known as "reverse socialization," it is well documented that children have significant influence on parents" decisions for household products, such as food and beverages (Chavda, Haley and Dunn 2005; Cowell 2001; Dholakia 1984; Ogba and Johnson 2009). It has been stated that this influence has increased recently due to "time poor" families where there are two working parents or a single parent in the household. Parents, now more than ever, encourage their children's participation in family decision-making (Chavda, Haley and Dunn 2005). Children's influence comes, in part, from what they have been exposed to in product marketing messages. Much of this information comes from advertising, and then children at the point of purchase recognize certain retrieval cues from the advertising on a product's packaging and influence the adult decision-maker to purchase the product that he/she recognizes and wants.

These visual cues used in advertising and integrated on product packaging are very meaningful to children. McNeal and Ji's (2003) analyzed product packaging as a communication tool for children, specifically in the cereal industry. They report that when asked to draw a cereal box, over 97 percent of children studied drew a cereal box with the brand name and brand-related symbols. The researchers concluded that children have the ability to elicit from memory elaborate visual cues and that much of these cues are taken from product packaging. Thus, if food and beverage marketers are marketing their products with fruit-related cues in the brand name or with fruit images on the packaging (e.g., Sunny Delight), then it is important to examine the conclusions that children draw from this brand and package information as it is used when they formulate their requests of their parents to buy.

\section{Brand Name and Packaging Signals}

Brand names and packaging serve as important cues or signals of brand information. For example, a brand name identifies the brand and differentiates it from competitors (Reece and Ducoffe 1987). Brand naming is the most basic form of familiarity for consumers, and can be regarded as a gateway to more complicated learning and memory of product information (Alba, Hutchinson, and Lynch 1991). In addition, the product's packaging is also important in conveying information (Blyth 2001). As the "silent salesman," (Roper and Parker 2006) packaging serves both physical and promotional purposes for marketers. In fact, packaging has been called the fifth 'P' of marketing (Kotler et al. 1999).

It has been reported that the average grocery store shopping experience lasts only 39 to 45 minutes, with this time decreasing for "time poor" working adults (Hamrick and Shelley 2005). During that time, evaluations and 
decisions are made very quickly. Knowing this, marketers use signals on their packaging in order to reinforce advertising messages, convey information quickly, and to induce buying. Brand Packaging Magazine states that packaging plays a strategic role in seven out of ten in-store purchase decisions (1999). Auh and Shih (2009) state that marketers use package signals to "convey and deliver a message that they would like their customers to accept and believe" (p. 440). Further, Auh and Shih (2009) explain that signals, taken together, help consumers understand a product from what information marketers make available through signals sent by various means. Finally, "73 percent of purchase decisions are made at the point of purchase with packaging as the key indicator or influencer on peoples' choice" (Ogba and Johnson 2010, p. 79). Thus, the consumer relies heavily on brand name and packaging to assist them in evaluating brands and making decisions to buy.

There have been a few studies that have examined the information processing of brand names and packaging for children. Macklin (1996) conducted three experiments with preschoolers and concluded that when brand names were accompanied by visual cues on packaging (picture and color), these names were better recognized and remembered by these children.

With regard to product selection, Marshall, Stuart and Bell (2006) examined the relationship between product packaging color and the selection of products among preschoolers for three food categories. Findings indicated that there is a strong relationship between favorite color and choice of product, suggesting that marketers should consider popular colors in package design for children's food product choices.

Others have examined packaging and food preferences and concluded that packaging indeed affects the food product preferences for children (Dammler and Middelmann-Motz 2002, Hill and Tilley 2002, Ogba and Johnson 2010, Silayoi and Speece 2004). However, while the impact of brand names and packaging on children's preferences for food products is well documented, the research in this area has not examined the impact of brand names and packaging on inferences (knowledge) children glean from these important marketing elements. This is extremely important today as the industry is being asked to play an important role in encouraging more nutritional consumption (FTC 2008). The focus has shifted from food marketing to healthy food marketing. What food marketers do to assist children in having a better understanding of nutritional content and nutritional eating is now the focus.

\section{Fruit and Fruit-like Products}

Fruit is known to have fiber, vitamins and minerals and children are taught at a very young age that fruit is good for them. Fruit contains Vitamin C and Vitamin C is a good cure for the common cold and may provide protection against immune system deficiencies. The Food Pyramid that children learn about in school suggests that children should have two to four servings of fruit per day and the Dietary Guidelines for Americans include fruit as a vital part of a nutritionally balanced diet.

With the above in mind, a study sponsored by Prevention Institute content analyzed 37 popular and highly advertised children's food products that had fruit signals in the brand name and/or packaging (Mikkelsen et al. 2007). The purpose of the content analysis was to assess whether the name and package signals actually represented the fruit content in the product. Only 12 of the 37 products actually contained real fruit or 100 percent real fruit juice. Nineteen of the products contained no fruit at all and of these 19,12 made clear references to fruit on the package. These references included graphical depictions of fruit, use of the name of a fruit like strawberry to explain the flavor of the product, use of the word "fruit" or "fruity" in the brand name or the phrase "fruit flavors" found somewhere on the package. This Prevention Institute study concluded that consumers and buyers of these products may have difficulty in perceiving these misleading signals found on popular children's food products. The study went further to suggest that consumers deserve more truthful disclosure.

During the year following the 2007 Prevention Institute study, the Strategic Alliance for Healthy Food and Activity Environments called on the food and beverage industry to respond to the findings of the study and make substantial changes in its packaging and naming strategies to assist in healthy eating choices by children. Prevention Institute re-examined the same products from the original study after one year (Chao, Chehimi, and Mikkelsen 2008). There were very few changes as a result of the 2007 study. Only two products from the original study 
removed references to fruit on the package and one product marketer even added a reference to fruit even though the product contained no real fruit. This is surprising given earlier cases brought before the Children's Advertising Review Unit (CARU) with similar claims.

The Children's Advertising Review Unit (CARU) routinely reviews all forms of marketing communications directed to children to determine if this communication has the potential to mislead child consumers. For example, in 2005, CARU reviewed the packaging for various Nabisco fruit snacks marketed by Kraft Foods. These fruit snacks included SpongeBob Squarepants Fruit Snacks, Kool-Aid Fruit Rolls and Capri Sun All Natural Fruit Rolls. The packaging for the SpongeBob Squarepants Fruit Snacks, for example, contained pictures of watermelon, raspberries, a strawberry, and a pineapple, and stated, "Fruit Snacks," "Made With Real Fruit Juices," "100\% DV VITAMIN C" and "Excellent Source of Vitamins A \& E." CARU questioned whether these packaging claims represented to children that these products contain fruit and little else, and that eating the products is nutritionally equivalent to eating a piece of fruit. The advertiser ultimately discontinued the use of the claim, "Made with Real Fruit Juice" and avoided depictions that could potentially overstate the presence of fruit or juice in the products targeting children (Case \#4336 (05/26/05).

The current research examines what it is that children infer from brand names and food packaging containing fruit signals to further understand inference-making by children with implications on food marketing practices, public policy and marketing ethics. While research has analyzed the content of these fruit-like products targeting children, very little research has actually studied the inferences made by children about the content of packaged foods. From this review of the literature, the first research question is presented.

RQ1: When exposed to food product brand names and packaging with fruit or fruit-like cues, what do children infer about the amount of fruit found in these packaged products?

\section{Developmental Differences Among Children}

The current research analyzes the inferences made by first and fourth grade children. These two age groups were selected as previous research has documented the developmental differences between these two age groups (Piaget 1970, 1971) and thus differences in the inferences made from brand names and packaging are expected.

Paiget states that 6 and 7 year old children (i.e., first graders) are "preoperational," meaning that they are more astute at processing directly observable than abstract or symbolic stimuli. They learn best from pictures instead of words (Chandler, Greenspan, and Barenboim 1973) and deductive reasoning is not well developed. Roedder-John (1999) suggests that older children (including fourth graders) between seven and 11 years of age are "cued processors" and can understand the intent of advertising and can also recognize deception in commercial messages. This age group is said to be in the formal operational stage (Piaget 1970, 1971). They can better understand symbols and metaphors in messages (Miller, Smith, and Goldman 1989). Previous research suggests that older children have greater sophistication in processing marketing cues. Nguyen (2008) found that children's ability to correctly classify foods as healthy or unhealthy improved with age which seems logical given the differences in cognitive abilities. The current research analyzes the differences in the inferences made and expects older children to be more accurate in their observations of fruit content. As this study is exploratory in nature, the following research question is presented:

RQ2: Do younger children and older children differ in their abilities to appropriately infer the amount of fruit in fruit and fruit-like packaged products?

\section{METHODOLOGY}

\section{Visual Stimuli and Measures}

The data were collected via questionnaires. Children were first presented with a test to determine their knowledge of fruit. They were presented with four images. These images included an apple, a carrot, broccoli, and a banana. They were asked to circle the images of fruits. Next, children were asked to complete a drawing task. 
They were asked to draw a picture of their favorite healthy food. A drawing task is considered to be a children centered research method that builds trust and rapport with child participants (Alderson 2000) and has been successfully used in child consumer marketing studies (McNeal and Ji 2003). Children were then asked to respond to 25 different products from the Prevention Institute content analysis study (for a list of the products used in the current study, see the Appendix). Images of product packages were taken from company websites in order to insure use of real and current packages. Each product package was presented in color on the survey and each question was read aloud. Children were asked to indicate the amount of fruit content in each product. Specifically, they were asked whether the product contained "a lot of real fruit," "a little real fruit," or "no real fruit." These labels were accompanied by a graphic ratings scale. Graphic ratings scales allow children to respond more easily (Barker and Weller 2003). A fruit bowl filled with fruit graphically represented the category of "a lot of real fruit." A picture of a fruit bowl with only an apple and a banana represented the "a little real fruit" category, while an empty fruit bowl represented the "no real fruit" category.

\section{Procedure and Data Collection}

A research assistant facilitated research sessions in classroom environments at two elementary schools. Each of the response categories and product images were explained to the groups of children. Children were asked to circle the fruit bowl that best matched the amount of fruit in the corresponding product positioned to the left of the ratings scale. Each research session lasted for approximately 25 minutes.

\section{Sample}

A sample of 169 first $(n=81)$ and fourth graders $(n=88)$ from two elementary schools participated in the study. The sample consisted of 107 girls and 62 boys. These children were recruited from two different school districts in the Northeastern region of the United States. One elementary school from each district was visited. Six classrooms from each school participated. Prior to the research session at each school, parental consent was obtained via a consent form. Teachers were incented to ask children to return the consent forms every day over a one week period. Teachers received $\$ 1.00$ for each consent form returned to be used to purchase something for the classroom.

\section{RESULTS}

\section{Fruit Knowledge Check}

In order to insure that children understood the concept of real fruit, they were first asked to circle images of fruit on the first page of the survey booklet. They were presented with images of an apple, a carrot, broccoli, and a banana. All but 11 children correctly differentiated the fruit from the other images. These 11 surveys were removed from the analysis.

\section{Drawing Task}

In order to further investigate Nguyen's (2008) findings which illustrated that children place fruit in a healthy food evaluative category, children were asked to draw their favorite healthy food. When asked to think about healthy foods, children indeed categorize fruit as healthy. There were 118 pictures of a fruit drawn. These fruits consisted of apples, bananas, grapes, oranges, cherries, grapefruit, kiwi, peaches, pears, pineapples, raspberries, strawberries, watermelon, and plums. This wide variety of fruits suggests that children have a rich understanding of fruit as healthy. Clearly, fruit is placed into the healthy food category. In 26 cases, vegetables were drawn. The remaining 25 illustrations were random from pizza to oatmeal. This drawing task suggests that children have strong perceptions of and liking for fruit as a healthy food and supports Nguyen's research regarding the placement of fruit in the evaluative category of healthy foods among children.

\section{Fruit Content Inferences}

In response to the first research question, a fruit inference score was created for each fruit content category. Correct responses were summed for a total score. Correct responses were recorded as 1 and incorrect responses 
were recorded as 0 . For the "no fruit" category, scores could range from $0-9$, with nine being 100 percent correct. The average score for correct responses was 2.03. With the exception of one product (i.e., a candy product), less than 40 percent of the respondents provided correct responses for each product in this category. That is, children were not able to infer that these products contained no real fruit when exposed to the products' names and packaging. In the "minimal fruit" category, scores could range from $0-6$, with six being the most correct. The average correct score was 2.63. While for two products in this category, correct inferences were made by over 50 percent of the respondents, the majority of respondents did not accurately infer the correct amount of fruit for the other four products in the minimal fruit category. Finally, in the "real fruit" category, the scores could range from 0 10, with 10 being 100 percent correct. The average correct score was 3.36. Responses were correct among 70 percent of the sample for one product in this category (i.e., Juicy Juice), however for the remaining nine products correct responses occurred less than 50 percent of the time. Overall, the average correct score for all three categories combined was 8.04 with 25 being the highest possible correct score. These results illustrate that children do not accurately infer fruit content from brand names and packaging that include fruit and fruit-like signals. See Table 1.

Table 1: Proportion of Fruit Content Inferences by Product

\begin{tabular}{|c|c|c|c|c|}
\hline \multirow[b]{2}{*}{ Product } & \multirow[b]{2}{*}{$\begin{array}{l}\text { Avg. } \\
\text { Correct } \\
\text { Score }\end{array}$} & \multicolumn{3}{|c|}{ Fruit Content Inferences } \\
\hline & & $\begin{array}{l}\text { \% Real } \\
\text { Fruit }\end{array}$ & $\begin{array}{c}\text { \%Minimal } \\
\text { Fruit }\end{array}$ & $\begin{array}{l}\% \text { No } \\
\text { Fruit }\end{array}$ \\
\hline Real Fruit or (100\% Fruit Juice) & $3.36 / 10.0$ & & & \\
\hline Apple Cinnamon Cheerios & & 12.4 & 62.1 & 25.4 \\
\hline Apple Jacks & & 19.5 & 52.1 & 28.4 \\
\hline Berry Burst Cheerios (Strawberry, Banana, and Triple Berry) & & 40.2 & 51.5 & 8.3 \\
\hline Eggo Waffles (Apple Cinnamon, Blueberry, Strawberry) & & 23.7 & 55.6 & 20.7 \\
\hline Kellogg's Strawberry Pop Tarts & & 27.8 & 56.8 & 15.4 \\
\hline Quaker Chewy 90 Calorie Granola Bars (Baked Apple) & & 47.3 & 46.2 & 6.5 \\
\hline Fruit Rollups (Strawberry) & & 22.6 & 40.5 & 36.9 \\
\hline Gushers Fruit Snacks (Strawberry) & & 28.0 & 33.3 & 38.7 \\
\hline Capri Sun Fruit Waves (Grape) & & 49.7 & 39.6 & 10.1 \\
\hline Juicy Juice & & 70.2 & 26.8 & 3.0 \\
\hline Minimal/Some Fruit or (2-10\% Fruit Juice) & $2.78 / 6.0$ & & & \\
\hline Sunny Delight & & 53.0 & 38.7 & 8.3 \\
\hline Capri Sun Juice Drink (Strawberry) & & 49.4 & 42.3 & 8.3 \\
\hline Hi-C Fruit Drink (Boppin Strawberry) & & 31.4 & 60.9 & 7.7 \\
\hline Kool-Aid Jammers & & 31.0 & 52.4 & 16.7 \\
\hline Popsicle (Orange, Cherry, Grape) & & 21.9 & 43.2 & 34.9 \\
\hline Skittles & & 21.3 & 24.3 & 54.4 \\
\hline No Fruit & $2.03 / 9.0$ & & & \\
\hline Tang & & 42.0 & 45.6 & 12.4 \\
\hline Air Heads & & 9.5 & 26.0 & 64.5 \\
\hline Berry Berry Kix & & 20.7 & 70.4 & 8.9 \\
\hline Captain Crunch with Crunch Berries & & 21.9 & 47.3 & 30.8 \\
\hline Dannon Danimals XL (Strawberry Explosion) & & 49.7 & 46.2 & 4.1 \\
\hline Fruit Loops & & 37.3 & 38.5 & 24.3 \\
\hline Fruity Cheerios & & 46.7 & 39.1 & 14.2 \\
\hline Trix Cereal & & 32.7 & 38.1 & 29.2 \\
\hline Yoplait Go-Gurt (Strawberry Splash) & & 34.9 & 51.5 & 13.6 \\
\hline Overall Average Total Correct Score & $8.04 / 25.0$ & & & \\
\hline
\end{tabular}

Note: Scores in bold are correct responses for each category of products

Corresponding to RQ2, fruit inference scores were compared between younger and older children as differences were expected due to differences in cognitive abilities. In the "no fruit" category of products, first 
graders scored a 1.49 with fourth graders scoring $2.52(\mathrm{p}=.000)$, a statistically significant difference with fourth graders being more accurate in their inferences of fruit content, albeit still quite inaccurate. In the "minimal fruit" category, first graders generated a score of 2.45 while fourth grade children reported a score of 2.78 . While fourth graders were again more accurate in their fruit inferences, the difference was not significantly different. In the "real fruit" category, surprisingly younger children were more accurate in their fruit content inferences with a score of 3.67 while the fourth graders reported a score of $3.08(\mathrm{p}=.049)$. Overall, fourth graders were more accurate in their total fruit content inferences with a total score of 8.33 compared to a score of 7.71 for first graders, however this comparison was not significantly different $(\mathrm{p}=.095)$. While there are some differences between the younger and older children in the fruit content inferences made, it should be noted that scores for both groups for each category of products were extremely low and that older children did not significantly outscore younger children. This is surprising due to their well-documented superior cognitive abilities, their understanding of the persuasive intent of marketing strategies, and their ability to perceive deception. See Table 2. Finally, it is important to note that boys and girls did not differ in their fruit inference scores, nor did children from the two different schools.

Table 2: Comparison of Mean Scores Between Grade Levels on Average Correct Fruit Content Inference Scores

\begin{tabular}{|c|c|c|c|c|}
\hline \multirow[t]{3}{*}{ Measure } & \multicolumn{2}{|c|}{ Age } & \multirow[t]{3}{*}{ t-stat. } & \multirow[t]{3}{*}{ p-value } \\
\hline & $1^{\text {st }}$ Grade & $4^{\text {th }}$ Grade & & \\
\hline & $\mathrm{n}=81$ & $\mathrm{n}=\mathbf{8 8}$ & & \\
\hline Real Fruit Inference Score & 3.67 & 3.08 & 1.985 & .049 \\
\hline Minimal Fruit Inference Score & 2.45 & 2.78 & -1.633 & .104 \\
\hline No Real Fruit Inference Score & 1.49 & 2.52 & -3.862 & .000 \\
\hline Overall Fruit inference Score & 7.71 & 8.33 & -1.678 & .095 \\
\hline
\end{tabular}

\section{DISCUSSION}

Utilizing an information processing framework, the current study examined the inferences made by children about the fruit content in many popular children's food and beverage products. There are many fruit signals in the brand names and packaging of children's food products. This exploratory study is one of the first investigations of the inferences made by children about the amount of fruit found in some popular children's food and beverage products. Children in this study drew pictures of healthy foods and were presented with pictures of food products, and asked to respond regarding the amount of fruit in the products using a graphic ratings scale. One of the most important findings from the study is that children clearly view fruit as a healthy food, as represented by their drawings, but when asked to infer the amount of fruit in commonly sold food products with fruit or fruit-like names and/or package symbols, they do not know which products contain real fruit and which do not.

The scores for each category of products were low, illustrating incorrect responses. Specifically, for products with no real fruit, some children inferred that these products contained a lot of real fruit. For instance, approximately 50 percent of the children in the study inferred that Dannon Danimals XL Strawberry Explosion Yogurt contained a lot of real fruit when actually the product contains no real fruit at all. By contrast, in the category of products containing a lot of real fruit, approximately 40 percent of the children inferred that fruit rollups and fruit gushers have no real fruit at all, when in fact both of these products contain a lot of real fruit (albeit a lot of sugar as well). Clearly, there is confusion in the children's marketplace for packaged fruit and fruit-like products.

The above discussion is troublesome when integrated with the results of the drawing task. If children do not accurately infer the amount of fruit in food and beverages from brand naming and packaging, they may also inaccurately infer the healthfulness of these products since they strongly believe that fruit is a healthy food. For example, 42 percent of the children in this study categorized Tang as having a lot of real fruit. Consequently, children may also infer that this product is healthy as they believe it has real fruit. In fact, Tang has no real fruit at all.

This investigation also examined the differences in inferences between first and fourth grade children. Even though there is a rich stream of research in developmental psychology and consumer behavior documenting the differences in children's processing and understanding of advertising, this study examined children's processing of product packaging and brand names. Specifically, it was expected that older children would more correctly infer 
the amount of fruit content in popular kids' food and beverage products. However, results illustrated that older children are really not superior to younger children in drawing correct inferences from brand names and packaging. In fact, in one category of products younger children were better. While research illustrates that older children understand the persuasive intent of advertising, it seems older children may put more trust and faith in packaging and naming. The ability to make accurate inferences from packaging and naming did not significantly improve with age in the current study. This has major implications as these elements of marketing have been found to affect the food product preferences for children (Dammler and Middelmann-Motz 2002, Hill and Tilley 2002, Ogba and Johnson 2010, Silayoi and Speece 2004). Children may be more easily deceived by brand naming and packaging, than by advertising.

\section{IMPLICATIONS FOR FOOD MARKETING, PUBLIC POLICY AND BUSINESS ETHICS}

At the very least, food marketers need to consider providing nutritional detail about these fruit-like products to show that they are not equivalent to fruit. It is assumed that children are not going to read nutritional labeling and due to time constraints, it is quite possible that neither will parents and caregivers. We do know that children read brand names and front of packaging elements (McNeal and Ji 2003). But because of the healthy halo surrounding fruit and fruit-like products and the strong feelings among children that fruit is healthy, it is important to make sure that children understand that some of these products do not contain real fruit and all of these products are not equivalent to eating real fruit. Future research should investigate how best to convey this information on the front of package to begin to dismiss the confusion.

Another strategy for food and beverage marketers would be to completely remove all references to fruit for products in the "no real fruit" category. Makers of Froot Loops and Trix have recently done this. Froot Loops removed the phrase, "Natural Fruit Flavors" and the accompanying cartoon-like fruit representations. The package does not contain any references to fruit today. Similarly, Trix cereal no longer presents fruit shapes on its packaging. These images are now simply round corn puffs. Other food and beverage marketers should consider this same strategy.

Future research should also examine whether the confusion exists among parents and caregivers. Children have significant pester power for food and beverage products, but ultimately parents are the deciders and buyers. It is unknown whether the same healthy halo exists for parents and whether or not they themselves can make accurate inferences from brand naming and packaging.

With approximately 10 percent of children (aged 2-5) being overweight leading to increased risk of heart disease, type 2 diabetes, and poor emotional health (American Heart Association 2006), food and beverage marketers have been asked to self-regulate. Clear brand naming, packaging and disclosure are important first steps. Much of the research being done to identify food marketing's role in combating childhood obesity has focused on advertising and regulating the messages presented to children via television and the online community (Desrochers and Holt 2007, Moore and Rideout 2007, Neuman 2011). The research presented here suggests more concentration on brand naming and packaging which are extremely powerful at the point of purchase. These elements have been identified as an area of possible market failure in the discussion of food marketing and childhood obesity (Goldberg and Gunasti 2007, Sieders and Petty 2007).

In addition to making strides for combating childhood obesity, marketing initiatives must be ethical. Bone and Corey (2000) state "marketing practices are often perceived by consumers to be the most unethical component of business" (pg. 199). They state that one reason for this may be that marketers' strategies are among the most visible to the public and under scrutiny of organizations such as the FTC and CARU. Brand names and packaging are certainly the most visible and are therefore a central focus in criticism about ethical decision-making among marketing professionals (Bone and Corey 2000). The research findings presented here lend support for the notion that there is confusion and the potential for deception in the marketplace, especially among young consumers as a result of the brand naming and packaging of popular children's food and beverage products. This finding raises ethical questions. 


\section{LIMITATIONS}

There are a few limitations of this exploratory study that should not go without mention. First, the measurement of inferences is difficult. Kardes (1993) mentions how measurement reactivity may occur when measuring inferences. That is, it is difficult to determine if respondents make inferences from to the stimulus or from the measurement. Also because there is a significant amount of advertising for food products to children, respondents more than likely, had previous exposure to many of the products under study. Thus, inferences may have come to some degree from product advertising. Priming respondents with a picture of the package and with verbal instructions hopefully minimized the effect of previous exposure to the product. However, the integration of advertising with brand naming and packaging should be investigated further to determine how marketing strategies together impact the inferences made about food and beverage products.

\section{CONCLUSION}

It is clear that marketing significantly affects children's food preferences, requests, and consumption. The Institute of Medicine (2006) states that by two years of age, most children can recognize products in supermarkets and ask for them by name. Therefore, an understanding of how children use brand names and packaging at the point of purchase in a supermarket environment is of critical importance to marketers and public policy. While the current restrictions on children's food advertising will reduce the amount of exposure that children have to food and beverage advertising, there are no restrictions on brand naming and packaging as it related to the current healthy food marketing environment. This research urges industry leaders such as Kraft and Kellogg's to extend their current initiatives regarding food advertising, package size, and product formations to include modifications to brand naming and product package design to assist children and parents in their evaluations of fruit and fruit-like products at the point of purchase. Further, this research calls for an examinations of children's food product brand names and packaging by industry regulatory bodies such as the Children's Advertising Review Unit (CARU) and the FTC. Regulatory alternatives for full disclosure should be explored.

\section{AUTHOR INFORMATION}

Jill K. Maher is a University Professor of Marketing in the School of Business at Robert Morris University. She obtained her Ph.D. in marketing from Kent State University. She has conducted and published consumer-oriented research in the Journal of Advertising Research, the Journal of Advertising, the Journal of Current Issues and Research in Advertising, the British Food Journal, the Journal of Nonprofit Management and Leadership, the Journal for the Advancement of Marketing Education, Food Policy, and the Journal of Marketing Management. E-mail: maher@rmu.edu

\section{REFERENCES}

1. Alba, J.W., J. W. Hutchinson, and J.G. Lynch, "Memory and decision-making," in Handbook of Consumer Behavior, (eds.) T.S. Robertson and H.S. Kassarjian, Englewood Cliffs, NJ: Prentice Hall, pp. 1-49, 1991.

2. Alderson, P., "Children as researchers: the effects of participation rights on research methodology," in Research with children: perspectives and practices, (eds.) Christiansen, P. and A. James, Falmer Press, London, pp. 241-257, 2000.

3. American Heart Association. Overweight in Children. http://www.americanheart.org, 2006. Accessed November 13, 2006.

4. Andrews, J. C., R.G. Netemeyer and S. Burton, Consumer generalization of nutrient content claims in advertising, Journal of Marketing, 62, pp. 62-75, 1998.

5. Auh, S. and E. Shih, "Brand name and consumer inference making in multigenerational product introduction context," Journal of Brand Management, 16:7, pp. 439-455, 2009.

6. Barker, J. and S. Weller, "Is it fun?: developing children centered research methods," The International Journal of Sociology and Social Policy, 23: 1/2, pp., 33-58, 2003.

7. Blackwell, R.D., P.W. Miniard, and J.F. Engel, Consumer Behavior, $10^{\text {th }}$ Edition, Thomson Southwestern, 2006.

8. Blyth, J., Essentials of Marketing, 2nd Edition, Harlow: FT-Prentice Hall, 2001. 
9. Bone, P. F. and R. J. Corey, "Packaging ethics: perceptual differences among packaging professionals, brand managers, and ethically-interested consumers," Journal of Business Ethics, 24, pp. 199-213, 2000.

10. Brand Packaging, How to get ideas on packaging that sells" http://www.brandpackaging.com/pront.html, 1999.

11. Chandler, M.J., S. Greenspan and D. Barenboim, "Judgments of intentionality in response to videotaped and verbally presented moral dilemmas: the medium is the message, Child Development, 44, pp. 315-320, 1973.

12. Chandon, P. and B. Wansink, "The biasing health halos of fast-food restaurant claims: lower calorie estimates and higher side-dish consumption intentions" Journal of Consumer Research, 34: October, pp. 301-314, 2007.

13. Chao, C., S. Chehimi, and L. Mikkelsen, "When will there be fruit? One year later: fruit content of the most highly-advertised children's foods and beverages," Prevention Institute, 2008.

14. Chavda, H., M. Haley and C. Dunn, “Adolescents' influence on family decision-making," Young Consumers, 6:3, pp. 68-78, 2005.

15. Cowell, P., Marketing to children: a guide for students and practitioners - part 2," The Marketing Review, 2, pp. 71-87, 2001.

16. Dammler, A. and A.V. Middelmann-Motz, "I want the one with Harry Potter on it," Advertising and Marketing to Children, 3: 2, pp. 3-8, 2002.

17. Dholakia, R., "Intergenerational differences in consumer behavior: some evidence form a developing country, Journal of Business Research, 12, pp. 19-34, 1984.

18. Desrochers, D.M., and D.J. Holt, "Children's exposure to television advertising: implications for childhood obesity, Journal of Public Policy and Marketing, 26: 2, pp. 182-201, 2007.

19. Federal Trade Commission, "Marketing food to children and adolescents: a review of industry expenditures, activities, and self-regulation," A report to Congress, July, 2008.

20. Goldberg, M.E. and K. Gunasti, "Encouraging an environment in which youths are encouraged to eat a healthier diet," Journal of Public Policy and Marketing, 26: 2, pp. 162-181, 2007.

21. Hamrick, K. and K.J. Shelley, "How much time do Americans spend preparing and eating food?" Amber Waves, November, pp. 10-11, 2005.

22. Hill, H. and J. Tilley, "Packaging of children's breakfast cereal: manufacturers versus children," British Food Journal, 104: 9, pp. 766-777, 2002.

23. Hoyer, W. D. and D. J. MacInnis, Consumer Behavior, 5th Edition, South-Western Publishing, 2010.

24. Institute of Medicine, Food marketing to children and youth: threat or opportunity? McGinnis J.M., Gootman J.A., Kraak V.I., (eds.), Washington, DC: The National Academy Press, 2006.

25. Jacoby, J., G.J. Szybillo, and J. Busato-Schach, "Information acquisition behavior in brand choice situations," Journal of Consumer Research, 3:4, pp. 209-217, 1977.

26. Kardes, F.R, "Consumer inference: determinants, consequences, and implications for advertising, "in Advertising Exposure, Memory and Choice, A.A. Mitchell (ed). Hillsdale, NJ: Erlbaum, 1993.

27. Kotler, P. G. Armstrong, J. Saunders, and V. Wong, Principles of Marketing, 2nd European Edition, London: Prentice Hall Europe, 1999.

28. Macklin, C.M., "Preschoolers' learning of brand names from visual cues," Journal of Consumer Research, 23:3, pp. 251-261, 1996.

29. Marshall, D., M. Stuart, and R. Bell, "Examining the relationship between product package colour and product selection in preschoolers," Food Quality and Preference, 17, pp., 615-621, 2006.

30. McNeal, J.U. and M.F. Ji, “Children's visual memory of packaging," Journal of Consumer Marketing, 20: 5, pp., 400-427, 2003.

31. Mikkelsen, L., C. Merlo, V. Lee, and C. Chao, "Where's the fruit? Fruit content of the most highlyadvertised children's food and beverages, Prevention Institute, 2007.

32. Miller, P.M., G.T. Smith and M.S. Goldman, "Emergence of alcohol expectancies in childhood: a possible critical period," Journal of Studies on Alcohol, 51 343-349, 1989.

33. Moore, E.S. and V.J. Rideout, "The online marketing of food to children: is it just fun and games?" Journal of Public Policy and Marketing, 26: 2, pp., 202-220, 2007.

34. Neuman, W., "U.S. seeks new limits on food ads for children," New York Times, April 28, 2011.

35. Nguyen, S.P., "Children's evaluative categories and inductive inferences within the domain of food," Infant and Child Development, 17, 285-299, 2008. 
36. Ogba, I. and R. Johnson, "How packaging affects the product preferences of children and the buyer behavior of their parents in the food industry," Young Consumers, 11:1, pp. 77-89, 2009.

37. Piaget, J., "The stages of the intellectual development of the child," in Readings in Child Development and Personality, P.H. Mussen, J.J. Conger and J. Kagan (eds.), New York: Harper and Row, 1970.

38. Piaget, J. Biology and Knowledge, Chicago: The University of Chicago Press, 1971.

39. Raghunathan, R., R.W. Naylor and W.D. Hoyer, "The unhealthy = tasty intuition and its effects on taste inferences, enjoyment and choice of food products, Journal of Marketing, 70: October, pp. 170-184, 2006.

40. Reece, B.B and R.H. Ducoffe, "Deception in Brand Names," Journal of Public Policy and Marketing, 6, pp. 93-104, 1987.

41. Roedder-John, D., "Consumer socialization of children: a retrospective look at twenty-five years of research," Journal of Consumer Research, 26: December, pp. 183-213, 1999.

42. Roper, S. and C. Parker, "How (and where) the mighty have fallen: branded litter," Journal of Marketing Management, 22:5/6, pp. 473-487, 2006.

43. Seiders, K. and R.D. Petty, "Taming the obesity beast: children, marketing, and public policy considerations," Journal of Public Policy and Marketing, 26: 2, pp. 23-242, 2007.

44. Silayoi P. and M. Speece, "Packaging and purchase decisions: an exploratory study on the impact of involvement level and time pressure," British Food Journal 106: 8, pp. 607-628, 2004.

45. Wansink, B. and P. Chandon, “Can 'low-fat' nutrition labels lead to obesity?" Journal of Marketing Research, XLIII: November, pp. 605-617, 2006. 


\section{APPENDIX}

\section{Product List}

Real Fruit or 100\% Fruit Juice

Apple Cinnamon Cheerios

Apple Jacks

Berry Burst Cheerios (Strawberry, Banana, and Triple Berry)

Eggo Waffles (Apple Cinnamon, Blueberry, Strawberry)

Kellogg's Strawberry Pop Tarts

Quaker Chewy 90 Calorie Granola Bars (Baked Apple)

Fruit Rollups (Strawberry)

Gushers Fruit Snacks (Strawberry)

Capri Sun Fruit Waves (Grape)

Juicy Juice

\section{Minimal/Some Fruit}

Sunny Delight

Capri Sun Juice Drink (Strawberry)

Hi-C Fruit Drink (Boppin Strawberry)

Kool-Aid Jammers

Popsicle (Orange, Cherry, Grape)

Skittles

\section{No Fruit}

Tang

Air Heads

Berry Berry Kix

Captain Crunch with Crunch Berries

Dannon Danimals XL (Strawberry Explosion)

Fruit Loops

Fruity Cheerios

Trix Cereal

Yoplait Go-Gurt (Strawberry Splash) 
NOTES 